\title{
Is There a Case for Recognising Taiwan at the International Science-Policy Interface for Climate Change?
}

\author{
Leslie Mabon ${ }^{1 *}$ and Wan-Yu Shih ${ }^{2}$ \\ ${ }^{1}$ School of Engineering and Innovation, The Open University, Milton Keynes, United Kingdom, ${ }^{2}$ Department of Urban \\ Planning and Disaster Management, Ming Chuan University, Taipei, Taiwan
}

Keywords: climate change, Taiwan, democracy-East Asia, global environmental politics, science-policy

OPEN ACCESS

Edited by:

Peter Haas,

University of Massachusetts Amherst,

United States

Reviewed by:

Chien-Yi Lu,

Academia Sinica, Taiwan

*Correspondence:

Leslie Mabon

leslie.mabon@open.ac.uk

Specialty section: This article was submitted to Climate and Decision Making,

a section of the journal

Frontiers in Climate

Received: 30 July 2021 Accepted: 22 September 2021 Published: 15 October 2021

Citation: Mabon L and Shih W-Y (2021) Is There a Case for Recognising Taiwan

at the International Science-Policy

Interface for Climate Change?

Front. Clim. 3:750443.

doi: 10.3389/fclim.2021.750443
Taiwan's response to COVID-19 has brought international recognition. Even with the first instances of sustained community transmission in 2021, cases and deaths have remained very low in comparison to other nations and outbreaks have quickly been brought under control. The pandemic has drawn attention to the capability of Taiwan to deliver an evidence-driven response to a complex issue-but also to Taiwan's marginal position in the international community. The fact that the country has suffered comparatively few cases of COVID-19 comes in spite of its exclusion from the World Health Organisation platforms for mutual support and knowledge-sharing (Nelson, 2020). As we look toward COP26 and the outputs of the IPCC's Sixth Assessment Cycle over 2021 and 2022, it is hence worth reflecting on Taiwan's position in the international community for another global science-policy challenge: climate change. In this opinion piece, we illustrate three ways in which Taiwan is marginalised within climate change action, and show why this may be problematic for a comprehensive and evidence-informed global climate response.

\section{DIRECT EXCLUSION FROM FORMAL INTERNATIONAL MECHANISMS FOR CLIMATE CHANGE NEGOTIATION}

The first way in which Taiwan is marginalised within global climate action is through direct exclusion from international negotiations and agreements. Taiwan is absent from the United Nations Framework Convention on Climate Change (UNFCCC) and hence from Conference of the Parties (COP) negotiations. Although Taiwan was an observer to the signing of the Paris Agreement in 2015, the administration of current President Tsai Ing-Wen has been increasingly restricted in opportunities to participate in international climate change conferences (Hioe, 2021) and is hence unlikely to have an official presence at COP26. Due to its lack of UN recognition Taiwan is also excluded from the Convention on Biological Diversity, another critical component of sustainability which is closely linked to climate change.

Taiwan's exclusion from the UNFCCC is problematic for two reasons. Firstly, Taiwan makes a disproportionately high contribution to global carbon dioxide emissions. Taiwan emitted 11.65 tonnes of $\mathrm{CO}_{2}$ per person in 2019, compared to a global average of 4.76 and 8.12 tonnes per person for PR China in the same year (EDGAR, 2021). Although Taiwan has voluntarily ratified global climate conventions and produced its own Intended Nationally Determined Contribution in line with the Paris Agreement, the Taiwanese Government has been criticised for a lack of conviction on putting its rhetoric of emissions reductions into practise (Chou, 2021). Inclusion within UNFCCC processes would thus create a legally-binding obligation for Taiwan as a high-emitting nation to reduce its emissions, and give the country greater impetus to turn its climate rhetoric into practise. 
Secondly, as well as agreement on legally-binding courses of action, international climate negotiations are also spaces for mutual learning and alliance building. Indeed, the fourth goal of COP26-Work Together to Deliver-is dedicated to collaboration to accelerate action to tackle the climate crisis (UN Climate Change Conference UK, 2021). A lack of recognition within the UNFCCC, and thus of access to spaces of negotiation and dialogue, limits Taiwan's opportunities for building alliances on climate action with other nations and for initiating global cooperation (Grano, 2019; Bezci, 2021). This again works both ways. On one hand, the current situation may limit other nations' opportunities to learn from areas in which Taiwan has made comparatively good progress, such as regional leadership in offshore wind energy (Chien, 2019), and digital technologies to enable participatory democratic approaches to environmental issues (Tang, 2019). On the other, Taiwan's marginal position may make it hard for Taiwan to form alliances with and learn from other nations who are leaders in areas where Taiwan is lagging, such as regulation of private sector high-emitters (Chou, 2021) and climate justice for indigenous peoples (Bayrak et al., 2020). This spirit of mutual learning leads to our second point: the diverging ways in which Taiwan is labelled by international organisations.

\section{MIS-RECOGNITION BY ORGANISATIONS OPERATING AT THE SCIENCE-POLICY INTERFACE}

A second way in which Taiwan is marginalised in the international arena on climate change action is through misrecognition or inconsistent recognition by international organisations working at the interface of science, policy and practise. Table 1 shows the titles used to identify Taiwan by a selection of international organisations working on climaterelated issues across science, policy and practise.

International organisations and networks play an important role in international peer-to-peer learning on climate change responses, especially between non-state actors who are not directly engaged in global climate agreements (e.g., Davidson et al., 2019; Frantzeskaki et al., 2019). Indeed, Taiwan has sought to engage widely with non-UN networks as part of what Biedermann (2017) calls a polycentric strategy to build global connectivity on climate issues in the absence of formal UNFCCC recognition.

However, effective peer-to-peer learning and opportunities to build global alliances rest on a clear understanding of the social and political formations that have shaped Taiwan's climate successes and failures to date. Particularly problematic is the labelling of Taiwan as "China" or a "Province of China," which may lead one to believe that data, reports, case studies or best practises from Taiwan are representative of conditions in PR China. As well as the different political formations in the two entities, with Taiwan being a multi-party democracy and PR China a one-party authoritarian state, the two entities have separate laws and systems for environmental protection, land use planning, public health and many others. The socio-economic and demographic profiles of the two also vary considerably. For instance, Taiwan's estimated GDP per capita for 2022 is 34,523USD; whereas PR China's is 10,500USD for 2020. Taiwan's Human Development Index equivalent score for 2019 was 0.916 (Rank 23 equivalent), whereas PR China's for the same year was 0.761 (Rank 85). Taiwan's Gini Coefficient (a measure of equality in society) was 33.7 in 2019, compared to 38.5 for PR China at the last measurement in 2016 (a score under 35 is considered to represent a low-inequality society). Taiwan's old age dependency ratio for 2020 was 22.53, whereas PR China's was 17.02 (National Statistics, 2021; World Bank, 2021).

Three examples illustrate why this mis-identification or exclusion of Taiwan may be problematic. Firstly, in 2018 the Intergovernmental Science-Policy Platform on Biodiversity and Ecosystem Services released their Regional Assessment Report for Asia and the Pacific (Karki et al., 2018). The assessment does not include any country-level data for Taiwan, and refers only twice to "Taiwan, China." Taiwan is not referred to at all in the final chapter on Options for Decision-Making Across Scales and Sectors, despite having potential to yield valuable insights for several of the areas covered in the chapter including community participation (Fan, 2016); recognition of local and indigenous people and their rights (Lin and Liu, 2016); and social and cultural instruments (Liao and Chan, 2016). The absence of Taiwan from the governance and policy sections of the assessment in particular limits opportunity for learning from potentially useful cases, and questions the completeness of what purports to be a "regional" assessment as it is unclear whether data pertaining to Taiwan across the synthesis is amalgamated with that of PR China or simply not included. Second, in 2015, the World Bank released a report titled East Asia's Changing Urban Landscape, which explored a breadth of challenges facing cities in East Asia, including implications of climate change for urban planning, land use and disaster risk (World Bank, 2015). As an example of best practise for sustainable urbanisation, the text refers to land pooling and readjustment techniques as a common practise in "Taiwan, China". Without explanation of the different policy and governance structures that exist between the entities in the report, as well as social norms around land ownership, it may not be apparent that the approach is contingent on the kinds of land ownership and local government arrangements found in Taiwan. For example, land in PR China belongs to either governments or communities, whilst in Taiwan $40 \%$ of land is privately owned. Third, ICLEI has created a library of case studies on governing the food-water-energy nexus, which includes a case study from Taipei alongside cases from Brazil, India, Madagascar, Malawi and South Africa (ICLEI, 2021). Whilst the Taipei case is listed as being from "Chinese Taipei," on reading the case it becomes apparent that the form of governance being promoted as a "success story" is contingent on the civil society participation in urban governance that Taiwan's democracy allows, and is created in response to a distinct ageing trend in Taiwanese society. Again, this country context-and its influence on what is presented-is not made apparent.

In a context of peer-to-peer learning and networking to support global climate responses, it is vital that an international audience is able to clearly view evidence shared by Taiwan 
TABLE 1 | Titles used to identify Taiwan by a selection of international organisations involved in climate-related issues.

\begin{tabular}{|c|c|c|}
\hline Organisation & Title used & URL \\
\hline IPCC & $\begin{array}{l}\text { Various: Taiwan, Province of } \\
\text { China; Taiwan, China; } \\
\text { Taiwan of China; Taiwan }\end{array}$ & $\begin{array}{l}\text { https://www.ipcc.ch/report/ar6/wg1/\#FullReport } \\
\text { https://www.ipcc.ch/report/ar5/wg2/ }\end{array}$ \\
\hline IPBES & Taiwan, China & https://ipbes.net/assessment-reports/asia-pacific \\
\hline UNDRR & Taiwan, Province of China & $\begin{array}{l}\text { https://data.humdata.org/dataset/gar15-global-exposure-dataset-for-taiwan-province-of- } \\
\text { china }\end{array}$ \\
\hline ICLEl & Chinese Taipei & https://iclei.org/en/members-search.html \\
\hline Global Covenant of Mayors & Chinese Taipei & https://www.globalcovenantofmayors.org/cities/east-asia/chinese-taipei/taipei/ \\
\hline Belmont Forum & Chinese Taipei & https://www.belmontforum.org/archives/resources/national-annex-most-chinese-taipei-ceh \\
\hline Future Earth & Taipei, Taiwan & https://futureearth.org/about/who-we-are/international-offices/taipei/ \\
\hline $\begin{array}{l}\text { International Science } \\
\text { Council }\end{array}$ & $\begin{array}{l}\text { China: Taipei } \\
\text { China, Academy of } \\
\text { Sciences Located in Taipei }\end{array}$ & https://council.science/member/china-taipei-academy-of-sciences-located-in-taipei/ \\
\hline World Bank & Taiwan, China & https://www.worldbank.org/content/dam/doingBusiness/country/t/taiwan-china/TWN.pdf \\
\hline Asian Development Bank & Taipei, China & https://www.adb.org/publications/taipei-china-fact-sheet \\
\hline $\begin{array}{l}\text { World Resources Institute } \\
\text { (Climate Data Explorer) }\end{array}$ & Taiwan, Province of China & https://cait.wri.org/business/table?countries=Taiwan\%2C\%20Province\%20of\%20China \\
\hline
\end{tabular}

as something enabled by the country's democratic governance structures, and reflective of the local socio-economic context. Yet the examples above show that the demarcation of Taiwan is far from clear or consistent in the networks through which this knowledge circulates. The implications of this inconsistent recognition for the evidence base supporting climate action form our third point: the confusion and conflation of Taiwan on the scientific record.

\section{CONFUSION AND CONFLATION OF TAIWAN WITH OTHER ENTITIES IN SCIENTIFIC EXCHANGE}

A third way in which Taiwan is marginalised in the international science-policy community for climate change is through misrecognition or inconsistent labelling within scientific exchange. This may create confusion for scientists wishing to learn from or build on existing outputs developed by others, or at worst lead to recommendations being based on erroneous interpretations of the underpinning evidence.

The inconsistency with which Taiwan as an entity is labelled is demonstrated in the most authoritative scientific texts on climate change-the IPCC Assessment Reports. The recently-released Working Group 1 report from the IPCC Sixth Assessment Cycle refers to Taiwan as "Taiwan" (e.g., pp. 9-128) and "Taiwan of China" (pp. 12-42). The Working Group 2 report from the Fifth Assessment Cycle refers to Taiwan variously as "Taiwan China” (p. 238), “Taiwan Province of China” (p. 1332), “Taiwan POC" (p. 678), and in some places simply as "Taiwan" (p. 421). The Working Group 3 report from the Fifth Assessment Cycle refers to Taiwan as "Taiwan Province of China" (p. 762), however contains a graph which treats Taiwan and PR China as separate entities, with Taiwan labelled as "Taiwan" (p. 790).
The divergent names used for Taiwan are perhaps most concerning in the WGII and WGIII reports, as these reports address Impacts, Adaptation and Vulnerability (WGII) and Mitigation of Climate Change (WGIII) - and hence reflect the social and cultural impacts of climate change, and the policy, economic and behavioural strategies which may support mitigation and adaptation. It cannot be assumed that global readers will be aware of the intricacies of the geopolitical situation between Taiwan and PR China, or of the different political systems and forms of social organisation between the two that we outlined in the previous section. Labelling Taiwan as "China" or a "Province of China" may lead one to erroneously believe that results from Taiwan reflect the situation in PR China and/or that PR China's climate policies are applicable to Taiwan.

Let us expand on the scientific problems associated with misrecognition of Taiwan by looking the peer-reviewed research on climate change itself. Meta-analysis and systematic review approaches are gaining traction in climate change scholarship to provide regional or global syntheses of state-of-the-art evidence to support policy and practise. Yet there are numerous cases where empirical research conducted in Taiwan is subsequently reported in meta-analyses as representative of "China."

We observe two ways in which this happens. In one, Taiwanese studies are identified as being from "China" when reported in regional or global meta-analyses. This practise can be seen, for example, in meta-analysis papers on land use dynamics and trajectories (Sonter et al., 2013); the relationship between urban configuration, energy consumption and carbon emissions (Chen and Chen, 2017); the role of trees in mitigating urban heat island effects (Rahman et al., 2020); and public health outcomes relating to air quality and climate (Cong et al., 2017). Yet Taiwan has different urban planning, land use and pollution control laws, energy mix and health systems to PR China. We would argue it is therefore methodologically problematic to report and metaanalyse work conducted in Taiwan as representative of "China," 
when the underpinning results are a product of very different social and political conditions to those found in PR China.

The second way in which Taiwan becomes misrepresented in the scientific record is at the country level, through metaanalyses which aggregate research about PR China and Taiwan to make claims about the situation in "China" as a single entity. This kind of research appears to be more common in environmental health, where meta-analyses into, for example, association between temperature and mortality (Luo et al., 2019), air pollution and adverse health effects (Lai et al., 2013), and ambient nitrogen dioxide and respiratory diseases (Sun et al., 2017) all mix data from PR China and Taiwan (plus in cases Hong Kong and Macau) to report on the linkages between aspects of climate change and public health in "China." In this case, what is methodologically problematic is that data collected from jurisdictions with differing health systems, environmental legislation and population demographics, as we illustrated previously, are mixed and used to represent health outcomes under climate change as if these areas are socio-economically and institutionally homogenous.

We do not intend to single out papers or authors for criticism here, or claim the results they report are invalid. We also acknowledge that country affiliations may be determined by editorial processes or institutional protocols, and are not necessarily the choice of study authors themselves. However, labelling Taiwanese cases as "China" in meta-analyses raises the risk of subsequent readers drawing erroneous conclusions about the underpinning socio-political context within which research results arise, especially for a global readership who may not be fully aware of the geopolitical situation. Getting this recognition right is especially important given the volume of research in climate-related fields that is produced by Taiwan. Despite its relatively small population (around 23 million people), Taiwan was ranked as the 23rd most productive country globally in the 2019-20 Nature Index for Earth and Environmental Sciences (Nature Index, 2020), and Scopus data shows that Taiwan is ranked in the top 10 countries globally for disaster science

\section{REFERENCES}

Bayrak, M. M., Hsu, Y.-Y., Hung, L.-S., and Tsai, H.-M. (2020). Global climate change and indigenous peoples in Taiwan: a critical bibliometric analysis and review. Sustainability 13:29. doi: $10.3390 /$ su13010029

Bezci, E. (2021). Seeking shelter in the anthropocene: challenges and opportunities for Taiwan. Pacific Rev. 1-26. doi: 10.1080/09512748.2021.1948912

Biedermann, R. (2017). Taiwan's polycentric strategy within the environmental regime complex on climate change. Asien 143, S25-S46. doi: 10.11588/asien.2017.144.14911

Chen, S., and Chen, B. (2017). Coupling of carbon and energy flows in cities: a meta-analysis and nexus modelling. Appl. Energy 194, 774-783. doi: 10.1016/j.apenergy.2016.10.069

Chien, K. (2019). Pacing for renewable energy development: the developmental state in Taiwan's offshore wind power. Ann. Am. Assoc. Geograph. 110, 793-807. doi: 10.1080/24694452.2019.1630246 research (Elsevier, 2016). Conflating Taiwan and PR China thus has the potential to lead to regional policy recommendations in areas such as climate risk reduction inadvertently being derived from data that mixes two entities with very different social and political structures.

\section{CONCLUSION}

Let us be clear. Our aim is not to "promote" Taiwan by uncritically holding it up as an exemplar of good practise for climate action. Taiwan has much to share internationally that other nations may learn from, yet there are many other elements of emissions reduction and environmental protection where Taiwan has significant room for improvement. Clearer delineation within the international scientific literature of data specific to Taiwan for issues such as emissions would make Taiwan's own obligations to the global climate effort more explicit, and greater opportunity for participation may enable Taiwan to learn from other countries globally. If nothing else, excluding Taiwan from global climate agreements means that a high-emitting country is absent from accords to keep global warming well below $1.5^{\circ} \mathrm{C}$ and protect biodiversity.

Science produced in and about Taiwan continues to contribute to global knowledge of climate change. More explicit and consistent recognition of Taiwan in the international arena through, for example the granting of observer status in international fora and the preservation of "Taiwan" as a separate country affiliation across scientific processes such as publication and review work, will reduce the risk of confusion and make it easier for a global audience to understand the distinct social and political context that is reflected in research about Taiwan.

\section{AUTHOR CONTRIBUTIONS}

LM and W-YS: conceptualisation, investigation, writingoriginal draft, and writing-review and editing. All authors contributed to the article and approved the submitted version.

Chou, B. (2021). Taiwan's climate change action on trial for the first time. News Lens Int. Edn. Available online at: https:/international.thenewslens.com/ article/154086

Cong, X., Xu, X., Zhang, Y., Wang, Q., Xu, L., and Huo, X. (2017). Temperature drop and the risk of asthma: a systematic review and meta-analysis. Environ. Sci. Pollut. Res. 24, 22535-22546. doi: 10.1007/s11356-017-9914-4

Davidson, K., Coenen, L., Acuto, M., and Gleeson, B. (2019). Reconfiguring urban governance in an age of rising city networks: a research agenda. Urban Stud. 56, 3540-3555. doi: $10.1177 / 0042098018816010$

EDGAR (2021). EDGAR - The Emissions Database for Global Atmospheric Research. Avaialble online at: https://edgar.jrc.ec.europa.eu/

Elsevier (2016). The Science of Disaster Science. Avaialble online at: https://www. elsevier.com/research-intelligence/campaigns/disastersci (accessed March 02, 2021).

Fan, M. F. (2016). Environmental justice and the politics of risk: water resource controversies in Taiwan. Human Ecol. 44, 425-434. doi: 10.1007/s10745-016-9844-7 
Frantzeskaki, N., Buchel, S., Spork, C., Ludwig, K., and Kok, M. T. J. (2019). The multiple roles of ICLEI: intermediating to innovate urban biodiversity governance. Ecol. Econ. 164:106350. doi: 10.1016/j.ecolecon.2019. 06.005

Grano, S. (2019). Climate Change Politics: Can These Raise Taiwan's International Recognition? Taiwan Insight. Available online at: https://taiwaninsight. org/2019/04/25/climate-change-politics-can-these-boost-raise-taiwansinternational-recognition/

Hioe, B. (2021). Cross-Strait Politics and the International Spectre of Climate Change in Taiwan. Taiwan Insight. Available online at: https://taiwaninsight. org/2021/03/25/cross-strait-politics-and-the-international-spectre- ofclimate-change-in-taiwan/

ICLEI (2021). IFWEN Case Study Series. Available online at: https://www.iclei.org/ en/publication/ifwen-case-study-series

Karki, M., Senaratna Sellamuttu, S., Okayasu, S., and Suzuki, W. (2018). IPBES: The Regional Assessment Report on Biodiversity and Ecosystem Services for Asia and the Pacific. Available online at: www.ipbes.net

Lai, H.-K., Tsang, H., and Wong, C.-M. (2013). Meta-analysis of adverse health effects due to air pollution in Chinese populations. BMC Public Health 13, 1-12. doi: 10.1186/1471-2458-13-360

Liao, K. H., and Chan, J. K. H. (2016). What is ecological wisdom and how does it relate to ecological knowledge? Landscape Urban Plann. 155, 111-113. doi: 10.1016/j.landurbplan.2016.07.006

Lin, P. S. S., and Liu, Y. L. (2016). Niching sustainability in an Indigenous community: protected areas, autonomous initiatives, and negotiating power in natural resource management. Sustain. Sci. 11, 103-113. doi: 10.1007/s11625-015-0294-8

Luo, Q., Li, S., Guo, Y., Han, X., and Jaakkola, J. J. K. (2019). A systematic review and meta-analysis of the association between daily mean temperature and mortality in China. Environ. Res. 173, 281-299. doi: 10.1016/j.envres.2019.03.044

National Statistics (2021). National Statistics, Republic of China (Taiwan). Available online at: https://eng.stat.gov.tw/mp.asp?mp=5

Nature Index (2020). Taiwan | Country outputs | Nature Index. Retrieved from: https://www.natureindex.com/country-outputs/taiwan (accessed October 19, 2020).

Nelson, C. W. (2020). COVID-19: time for WHO to reconsider its stance towards Taiwan. Nature 579:193. doi: 10.1038/d41586-020-00693-2
Rahman, M. A., Stratopoulos, L. M. F., Moser-Reischl, A., Zölch, T., Häberle, K. H., Rötzer, T., et al. (2020). Traits of trees for cooling urban heat Islands: a meta-analysis. Build. Environ. 170:106606. doi: 10.1016/j.buildenv.2019.106606 Sonter, L. J., Barrett, D. J., Moran, C. J., and Soares-Filho, B. S. (2013). A land system science meta-analysis suggests we underestimate intensive land uses in land use change dynamics. J. Land Use Sci. 10, 191-204. doi: 10.1080/1747423X.2013.871356

Sun, J., Barnes, A. J., He, D., Wang, M., and Wang, J. (2017). Systematic review and meta-analysis of the association between ambient nitrogen dioxide and respiratory disease in China. Int. J. Environ. Res. Public Health 14:646. doi: 10.3390/ijerph14060646

Tang, A. (2019). Inside Taiwan's New Digital Democracy. Actas Del III Congreso Internacional Move.Net Sobre Movimientos Sociales y TIC (Seville), 217-221.

UN Climate Change Conference UK (2021). 'COP26 Goals' UN Climate Change Conference UK 2021. Available online at: https://ukcop26.org/cop26-goals/

World Bank (2015). East Asia's Changing Urban Landscape: Measuring a Decade of Spatial Growth. Washington DC.

World Bank (2021). China | Data. Available online at: https://data.worldbank.org/ country/china

Conflict of Interest: The authors declare that the research was conducted in the absence of any commercial or financial relationships that could be construed as a potential conflict of interest.

Publisher's Note: All claims expressed in this article are solely those of the authors and do not necessarily represent those of their affiliated organizations, or those of the publisher, the editors and the reviewers. Any product that may be evaluated in this article, or claim that may be made by its manufacturer, is not guaranteed or endorsed by the publisher.

Copyright () 2021 Mabon and Shih. This is an open-access article distributed under the terms of the Creative Commons Attribution License (CC BY). The use, distribution or reproduction in other forums is permitted, provided the original author(s) and the copyright owner(s) are credited and that the original publication in this journal is cited, in accordance with accepted academic practice. No use, distribution or reproduction is permitted which does not comply with these terms. 